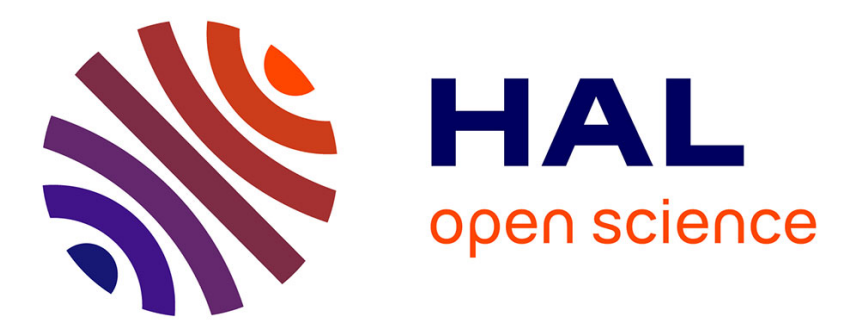

\title{
The influence of plane of section on the identification of bone tissue types in amniotes with implications for paleophysiological inferences
}

\author{
Mathieu G. Faure-Brac, François Pelissier, Jorge Cubo
}

\section{To cite this version:}

Mathieu G. Faure-Brac, François Pelissier, Jorge Cubo. The influence of plane of section on the identification of bone tissue types in amniotes with implications for paleophysiological inferences. Journal of Morphology, 2019, 280 (9), pp.1282-1291. 10.1002/jmor.21030 hal-02447352

HAL Id: hal-02447352

https://hal.science/hal-02447352

Submitted on 16 Oct 2020

HAL is a multi-disciplinary open access archive for the deposit and dissemination of scientific research documents, whether they are published or not. The documents may come from teaching and research institutions in France or abroad, or from public or private research centers.
L'archive ouverte pluridisciplinaire HAL, est destinée au dépôt et à la diffusion de documents scientifiques de niveau recherche, publiés ou non, émanant des établissements d'enseignement et de recherche français ou étrangers, des laboratoires publics ou privés. 
1 The influence of plane of section on the identification of bone tissue types in amniotes with

2 implications for paleophysiological inferences

3

4 Running title : Assessment of bone tissue types

5

6 Mathieu G. Faure-Brac, François Pelissier and Jorge Cubo

7 Sorbonne Université, MNHN, CNRS, Centre de Recherche en Paléontologie - Paris (CR2P) -

84 place Jussieu, BC 104, 75005 Paris, France.

9

10 Correspondence : $\underline{\text { Jorge.cubo_garcia@sorbonne-universite.fr }}$

12 Research Highlights : We show that the presence of canaliculi running radially from large

13 irregular osteocyte lacunae, and general isotropy at tissue scale, but local anisotropy at

14 cellular scale, offer reliable characters for diagnosing woven bone in amniotes. 
16 Abstract

17 The proportion of woven bone (WB) to parallel-fibered bone has been extensively used to

18 infer bone growth rates and resting metabolic rates of extinct organisms. The aim of this study

19 is to test in a variety of amniotes how reliably WB content can be measured using transverse

20 sections. For this we analyzed femoral transverse mid-diaphyseal thin sections of 14 extant

21 and extinct taxa and the corresponding longitudinal sections at a slightly metaphyseal level for

22 comparative purposes. We used the following characters to identify WB in transverse sections

23 because they are known to be distinct from those observed in parallel-fibered bone: an

24 isotropic bone matrix at tissue scale; an anisotropic microlamellar arrangement in former

25 osteoblast secretory territories at cellular scale; no alignment between osteocytes; and

26 canaliculi running radially from large irregular osteocyte lacunae. Our null hypothesis

27 predicts no differences between the amount of WB quantified in the transverse and the

28 longitudinal sections of a given long bone. Qualitatively, when a stripe or a patch of WB was

29 identified in a transverse section, the corresponding stripe or patch of WB was always found

30 at the same location in the corresponding longitudinal section. Quantitatively, a Wilcoxon

31 signed-rank non-parametric paired test did not detect a significant difference in the WB

32 content of the two section planes. Thus the null hypothesis is not rejected. Considering that

33 paleohistology is a destructive method, we recommend a workflow to efficiently establishing

34 the proportion of WB: quantifying it in transverse sections; preparing and analyzing

35 longitudinal sections only in cases where an ambiguity remains; reanalyzing the

36 corresponding transverse sections.

37 Keywords: anisotropy, bone histology, isotropy, parallel-fibered bone, woven bone 
Introduction

In vertebrate paleontological studies, bones constitute the large majority of fossilized remains. The histological analysis of skeletal elements allows to infer bone growth rates (Botha-Brink \& Smith, 2011; Cubo, Le Roy, Martinez-Maza, \& Montes, 2012; Padian, De Ricqlès, \& Horner, 2001; Padian, Horner, \& De Ricqlès, 2004), lifestyle (Houssaye, 2013; Houssaye et al., 2013; Laurin, Canoville, \& Germain, 2011), biomechanical constraints (Cubo, Woodward, Wolff, \& Horner, 2015) or metabolic rates (Cubo \& Jalil, 2019; Fleischle, Wintrich, \& Sander, 2018; Legendre, Guénard, Botha-Brink, \& Cubo, 2016; Olivier, Houssaye, Jalil, \& Cubo, 2017). Traditionally, bone paleohistology was based on the analysis of transverse sections (e.g., all the references cited above). Paleohistologists defined two characters using this material. The first one concerns bone matrix organization and has three states: presence of woven-fibered bone matrix (WB), presence of parallel-fibered bone matrix (PFB) and presence of lamellar bone matrix (LB) (Francillon-Vieillot et al., 1990). The second one is based on the organization of bone as a tissue and has two states: presence of lamellar-zonal bone (LZB) and presence of fibro-lamellar bone (FLB) (Francillon-Vieillot et al., 1990). Prondvai, Stein, de Ricqlès, \& Cubo (2014) proposed a development-based nomenclature in which LB is a particular type of PFB and FLB is a particular case of woven-parallel complex. According to Francillon-Vieillot et al. (1990), two osteohistological features can be used to identify WB and PFB: (1) collagen fiber orientation (inferred from the presence or absence of birefringence under cross-polarized light) and (2) morphology and spatial distribution of osteocyte lacunae. Under cross-polarized light, a highly organized matrix with fibers running parallel (oriented in the same direction; PFB) is anisotropic and appears bright (birefringent) when fibers are perpendicular to the axis of light propagation and it appears dark when fibers are aligned along the axis of light propagation (Bromage et al., 2003). Thus, in transverse thin sections, collagen fibers parallel to the main axis of a long bone appear dark. At low 
magnification (at tissue scale), the poorly organized matrix of woven bone shows intermediate brightness values (Bromage et al., 2003), or "general isotropy" (Francillon-Vieillot et al., 1990) from all cutting directions. However, at high magnification (on cellular scale), considering that WB collagen fibers are parallel in former osteoblast secretory territories ("microlamellar arrangement"), they are anisotropic and they appear bright where they are perpendicular to the axis of light propagation (Kerschnitzki et al., 2011). The other osteohistological feature, the morphology and spatial distribution of osteocyte lacunae, reflects (i.e., is correlated to) the extracellular matrix organization (Kerschnitzki et al., 2011). In PFB the longitudinal axis of osteocyte lacunae is parallel to collagen fiber direction whereas canaliculi are perpendicular to it (Kerschnitzki et al., 2011). In contrast, in WB there is no alignment between osteocytes and canaliculi run radially from osteocyte lacunae (Kerschnitzki et al., 2011).

Stein \& Prondvai (2014) drew attention to the fact (known previously but neglected before 2014) that WB, and PFB with fibers parallel to the main axis of the long bone, both appear dark in transverse thin sections. Considering that the proportion of WB to PFB has been extensively used to infer bone growth rates and resting metabolic rates of extinct organisms, mismeasure of WB content in transverse sections may have important paleophysiological consequences. The aim of this study is to test in a variety of amniotes the null hypothesis that WB content is not significantly different in the transverse and the longitudinal section planes.

\section{Material and Methods}

We analyzed femoral mid-diaphyseal transverse and slightly metaphyseal longitudinal thin sections of 14 extant and extinct taxa including five synapsids, three lepidosaurs, two testudines and four archosauromorphs. The transverse sections of most of them were prepared and used by Montes et al. (2007): Chelodina oblonga (Gray, 1841), Crocodylus niloticus 
88 (Laurenti, 1768), Gallus gallus (Linnaeus, 1758), Pelodiscus sinensis (Wiegmann, 1835),

Varanus exanthematicus (Bosc, 1792), Varanus niloticus (Linnaeus, 1766) and Zootoca

vivipara (Von Jacquin, 1787). We prepared the corresponding longitudinal thin sections using

the remaining slightly metaphyseal bone samples that were conserved embedded in epoxy resin. Vivian de Buffrénil kindly shared with us the femur of a growing Caiman crocodilus (Linnaeus, 1758), that was embedded in epoxy resin and cut both transversally and longitudinally. The transverse sections of four (of the five) synapsids were prepared and used by Olivier et al. (2017): Capreolus capreolus (Linnaeus, 1758), Lepus europaeus (Pallas, 1778), Lystrosaurus sp., and Oudenodon bainii Owen 1860. We used the remaining slightly metaphyseal bone samples (conserved embedded in epoxy resin) to perform the corresponding longitudinal thin sections. Transverse and longitudinal sections of the fifth synapsid of the sample (Clepsydrops collettii Cope 1875) and of the archosauromorph Azendohsaurus laaroussii Dutuit 1972 were prepared and used respectively by Laurin \& Buffrénil (2016) and by Cubo \& Jalil (2019). For further information on the ontogenetic stage of the specimens, see Supplementary file 1 . It is expressed as \% of adult body mass in extant species and inferred from bone histology in extinct ones. To check whether WB can be diagnosed in a reliable way we used a sample including different ontogenetic stages, different thermometabolic regimes (endotherms and ectotherms), and extant and extinct species of diverse amniote clades.

Transverse sections were available because they have been used in previous studies (see above). The corresponding longitudinal thin sections, $100 \pm 10 \mu \mathrm{m}$ thick, were obtained from slightly metaphyseal samples of the same specimens using the protocol described by Montes

110 et al. (2007). Thin sections were photographed using a Nikon Eclipse E600POL microscope under linearly polarized light and cross-polarized light with lambda wave plate. Thin sections were deposited at the vertebrate hard tissues histological collection of the French National 
113 Museum of Natural History (MNHN), where they are available upon request to the curator

114 (accession numbers of the thin sections analyzed in this study are given in Supplementary file

115 1). Bone histology nomenclature follows Francillon-Vieillot et al. (1990) with addenda from

116 Prondvai et al. (2014).

117 For each taxon included in this study transverse sections were analyzed first. In transverse

118 sections, bone matrix appearing yellow/orange or blue under cross-polarized light with

119 lambda wave plate, or bright without lambda wave plate, is composed of PFB with fibers

120 perpendicular to the main axis of the long bone. In these transverse sections, at low

121 magnifications (at the tissue level), bone matrix appearing red under cross-polarized light with

122 lambda wave plate, or black without lambda wave plate, is composed of either WB or PFB

123 with fibers parallel to the main axis of the long bone. Please note that at high magnifications

124 (at the cellular level), woven bone is anisotropic because of the presence of microlamellar

125 arrangement in former osteoblast secretory territories (fibers appear yellow/orange or blue

126 where they are perpendicular to the axis of light propagation; white arrow in Figure 1). We

127 encircled WB areas in transverse sections and measured these areas using ImageJ when we

128 observed: (a) a bone matrix showing general isotropy at low magnification (at tissue scale);

129 (b) an anisotropic microlamellar arrangement at high magnification (on cellular scale); (c) no

130 alignment between osteocytes, and (d) canaliculi running radially from large irregular

131 osteocyte lacunae. Longitudinal sections were analyzed likewise in a second time. Please note

132 that the channels herein referred to as vascular cavities are known to not be exclusively filled

133 with corresponding veins and arteries but accommodate a few more tissues as well such as

134 nerves and lymphatic vessels (Starck \& Chinsamy, 2002).

135 We tested the null hypothesis suggesting that the proportion of WB (expressed in percentage:

136 WB area / Total matrix area) is not significantly different in transverse and in longitudinal

137 sections. For this first we performed Shapiro-Wilk normality tests for the proportion of WB in 
138 transverse and in longitudinal sections in R (R Development Core Team, 2008). Second, we

139 tested the null hypothesis using a Wilcoxon signed-rank non-parametric paired test in $\mathrm{R}$ ( $\mathrm{R}$

140 Development Core Team, 2008) because the proportions of WB in transverse and in

141 longitudinal sections are not normally distributed.

142 Results

143 We analyzed qualitatively and quantitatively femoral transverse and longitudinal bone thin 144 sections of the fourteen taxa of the sample in order to test whether the quantified amount of

145 WB is the same in both section planes. First we provide detailed qualitative histological

146 descriptions of six species of the sample: two extant endotherms (Capreolus capreolus and

147 Gallus gallus, Figure 2), two extant ectotherms (Crocodylus niloticus and Zootoca vivipara,

148 Figure 3) and two extinct taxa (Lystrosaurus sp. and Oudenodon bainii, Figure 4). The

149 remaining taxa are briefly discussed later on in this section and are shown in supplementary

$150 \quad$ file 2.

151 The femoral transverse section of Capreolus capreolus (Figure 2A, B) is composed of laminar

152 bone. It contains vascular cavities circumferentially parallel to the periosteum with rare radial

153 anastomoses (Figure 2B, black arrow). Lining these cavities there are thin layers of

154 anisotropic LB (Figure 2B, white arrowhead) containing fibers running perpendicular to the

155 axis of light propagation (appearing bright blue or yellow under cross-polarized light with

156 lambda wave plate), fibers running parallel to the axis of light propagation (appearing as thin

157 black lines), and flattened osteocyte lacunae with the main axis oriented parallel to the

158 periosteal margin. Between two consecutive vascular cavities surrounded by LB we observe

159 large areas appearing red under cross-polarized light with lambda wave plate (black

160 arrowhead in Figure 2B). In these areas collagen fibers can be either woven or longitudinally

161 organized parallel to the long axis of the bone (and so cut transversally). The small size of the 
162 osteocyte lacunae of these areas (Figure 2B, black arrowhead) suggests that it is composed of

163 PFB cut transversally. Finally, under cross-polarized light with lambda wave plate, we always

164 observe bluish stripes (Figure 2B, white arrow) equidistant from two consecutive vascular

165 cavities. The large size and irregular shape of osteocyte lacunae of these areas suggest that it

166 is composed of WB (Figure 2B, white arrow). The bluish aspect of these stripes (Figures 1

167 and 2B, white arrows) may be linked to the microlamellar arrangement of collagen fibers in

168 WB at cellular scale (Kerschnitzki et al. 2011). The analysis of the corresponding longitudinal

169 section (Figure 2C, D) is congruent with this interpretation because the entire section but the

170 WB area (Figure 2D, white arrow) is strongly anisotropic. Note however that the WB area

171 (Figure 2D, white arrow) is not entirely red but rather dark purple under cross-polarized light

172 with lambda wave plate because of the microlamellar arrangement. The LB (Figure 2D, white

173 arrowhead) is composed of alternating anisotropic layers of fibers oriented either parallel to

174 the main axis of the bone (appearing blue because they are perpendicular to the axis of light

175 propagation), or perpendicular to the main axis of the bone and parallel to the axis of light

176 propagation (appearing as black lines). The PFB is anisotropic and appears bright blue under

177 cross-polarized light with lambda wave plate in longitudinal section (Figure 2D, black

178 arrowhead) because collagen fibers run parallel to the main axis of the bone (and so are

179 perpendicular to the axis of light propagation). It contains spindle shaped osteocyte lacunae

180 (Figure 2D, black arrowhead). In summary, there is a scaffold of WB trabeculae containing

181 large primary osteons formed by a peripheral thick layer of PFB and a inner thin layer of LB

182 around the vascular cavities (Figure 2 A-D).

183 The femoral transverse section of Gallus gallus is characterized by a radial pattern of vascular

184 cavities (Figure 2E, F). These ones are lined by anisotropic PFB (Figure 2F, black

185 arrowhead). Between these layers of PFB, we can observe areas of isotropic bone matrix

186 (Figure 2F, white arrow). The large size and irregular shape of osteocyte lacunae of these 
isotropic areas suggests that it is composed of woven bone. The analysis of the corresponding longitudinal section (Figure $2 \mathrm{G}, \mathrm{H}$ ) is congruent with this interpretation. We can observe areas of WB (Figure 2H, white arrow) and areas of PFB (Figure 2H, black arrowhead).

The femoral transverse section of Crocodylus niloticus is organized into three regions (white bar in Figure 3B). It contains longitudinal vascular canals without anastomoses (Figure 3A, B). Some of them are surrounded by an anisotropic tissue (blue and yellow under crosspolarized light with lambda wave plate in Figure 3B, white arrow) indicating the presence of PFB forming primary osteons. Others are simple vascular canals (Figure 3B, black arrow) and are preferentially located in the outer half of the cortex. The inner region is formed by a layer of endosteal bone around the medullary cavity (Figure 3B, D white arrow-heads). This endosteal layer is anisotropic in the longitudinal section (Figure 3D, white arrow-head), whereas it appears blue and red in the transverse section (Figure 3B, white arrow-head), indicating that it is probably composed of spiraling PFB at low angle to the bone's long axis. In the central region (in between the endosteal bone and the outer half of the cortex), in between primary osteons, the bone matrix is isotropic. It contains irregular large osteocyte lacunae (Figure 3B, black arrow-heads) suggesting that this matrix is composed of WB. The bone matrix of the outer half of the cortex appears blue at some locations, indicating that it is composed of PFB, and red at other locations, suggesting that it is formed by either WB or by PFB with fibers oriented parallel to the main axis of the bone. The small size of the osteocyte lacunae suggests that the second interpretation is correct. The longitudinal section was prepared from a slightly different (more metaphyseal) region and it contains only the endosteal layer and an outer region corresponding to the outer half of the cortex observed in the transverse section (bar in Figure 3D). The layer of endosteal bone is anisotropic (see above), suggesting that it is formed by PFB. The bulk of the cortex contains simple vascular canals (Figure 3D, black arrow) that appear elongated because they are parallel to the main 
212 axis of the long bone (they appear rounded in the transverse section; Figure 3B, black arrow).

213 The bone matrix of this region is anisotropic, suggesting that it is mainly composed of

214 longitudinal PFB (Figure 3D). Note, however, that it may contain a few transversally oriented

215 collagen fibers relative to the main axis of the long bone because bone matrix appears partly

216 blue in the transverse section; Figure 3B).

217 The femoral transverse section of Zootoca vivipara (Figure 3E, F) is completely avascular. It

218 contains an endosteal layer of PFB (Figure 3F, white arrow-head) and an outer periosteal

219 region that is also composed of PFB according to overall birefringence under cross-polarized

220 light with lambda wave plate. The longitudinal section also shows birefringence (Figure $3 \mathrm{H}$ ).

221 These observations suggest that the PFB forming the periosteal bone cortex probably contains

222 spiraling fibers at about $45^{\circ}$ to the bone's long axis.

223 The femoral transverse section of Lystrosaurus sp. is characterized by a pattern of

224 longitudinal vascular cavities (Figure 4A, B). These ones are lined by anisotropic PFB

225 forming primary osteons (Figure 4B, white arrowheads). These primary osteons are separated

226 by areas of isotropic bone matrix (Figure 4B, white arrows). The large size and irregular

227 shape of osteocyte lacunae in these isotropic areas suggests that it is composed of WB. The

228 analysis of the longitudinal section shows that the vascular canals have an elongated aspect

229 aligned to the main axis of the bone (Figure 4C, D). These cavities are lined by PFB forming

230 primary osteons (Figure 4D, white arrowheads). In between these primary osteons we can see

231 isotropic areas composed of WB (Figure 4D, white arrows).

232 Transverse and longitudinal femoral sections of Oudenodon bainii (Figure 4E-H) show a

233 pattern similar to that described for Capreolus capreolus : there is a scaffold of trabeculae

234 containing WB (Figure 4F, H, white arrows) and, in-between two layers, there are primary

235 osteons (vascular cavities lined by LB; Figure 4F, H, white arrowheads). Please note that in 
236 the transverse section of Oudenodon vascular cavities are not as regularly circumferentially

237 parallel to the periosteum as in Capreolus.

238 The analysis of the six taxa described above, and of the remaining taxa (shown in

239 supplementary file 2: Azendohsaurus laaroussii, Caiman crocodilus, Chelodina oblonga,

240 Clepsydrops collettii, Lepus europaeus, Pelodiscus sinensis, Varanus exanthematicus and

241 Varanus niloticus) reveals no incongruences between what is observed in the transverse

242 sections and what is observed in the longitudinal ones. When the presence of a) general

243 isotropy, b) a microlamellar arrangement in former osteoblast secretory territories, c) no

244 alignment between osteocytes, and d) canaliculi running radially from large irregular

245 osteocyte lacunae, suggested the presence of a patch or a stripe of WB in a transverse section,

246 the analysis of the corresponding longitudinal section confirmed the presence of such stripe or

247 patch of WB at the same relative location. Please find in supplementary file 2 pictures of all

248 transverse and longitudinal sections analyzed in this study where WB areas, PFB areas and

249 vascular canals were encircled.

250 Quantifications of proportion of WB in transverse and longitudinal sections are given in Table

251 1. Shapiro-Wilk normality tests showed that the proportion of WB was not normally

252 distributed neither in transverse $(p$-value $=0.02398)$ nor in longitudinal $(p$-value $=0.04465)$

253 sections. A Wilcoxon signed-rank non-parametric paired test did not reject the null hypothesis

254 suggesting that the proportion of WB (expressed in percentage: WB area / Total matrix area)

255 is not significantly different in transverse and in longitudinal sections ( $\mathrm{p}$-value $=0.9056$ ). In

256 other words, the Wilcoxon signed-rank non-parametric paired test did not detect a significant

257 difference in the WB content of the two section planes.

258 Discussion 
259 Stein \& Prondvai (2014) analyzed the bone histology of sauropod dinosaurs using transverse

260 and longitudinal sections and concluded that the amount of woven bone has been

261 overestimated in previous studies that used only transverse sections. They suggested that this

262 is because, under cross-polarized light, WB and PFB with fibers parallel to the main axis of

263 the long bone, both appear isotropic (dark) in transverse thin sections. Considering that the

264 proportion of WB to PFB has been widely used to perform paleobiological inferences of bone

265 growth rates and resting metabolic rates (see below), the bias put in evidence by Stein \&

266 Prondvai (2014) in sauropod dinosaurs, if proven by comparative data in other taxa, may have

267 important paleophysiological consequences. First, we elaborate on why quantifying the

268 proportion of WB is relevant in paleobiology by analyzing the relationships between this

269 feature and bone growth rates and resting metabolic rates. Afterwards we test the null

270 hypothesis that WB content is not significantly different in the transverse and the longitudinal

271 section planes. Finally, we propose recommendations and a workflow based on our findings.

272 WB is formed by the process of static osteogenesis: mesenchymal cells differentiate into

273 stationary osteoblasts oriented randomly, which differentiate into osteocytes in situ (Cubo,

274 Hui, Clarac, \& Quilhac, 2017; Ferretti, Palumbo, Contri, \& Marotti, 2002; Marotti, 2010;

275 Palumbo, Ferretti, \& Marotti, 2004). PFB is formed by the process of dynamic osteogenesis:

276 mesenchymal cells differentiate into osteoblasts that are all oriented in the same direction and

277 move back as they secrete osteoid, forming a migrating lamina of osteoblasts (Cubo et al.,

278 2017; Ferretti et al., 2002; Marotti, 2010; Palumbo et al., 2004). We will consider the

279 relationships between WB and bone growth rate at three levels: tissue, cellular and

280 ultrastructural (see Stein \& Prondvai, 2014, for a detailed review). At the tissue level, during

281 the initial growth stages, a number of amniotes form an initial scaffold made of WB that

282 includes large cavities and produces a rapid volume expansion of the cortex (e.g. Castanet,

283 Curry, Cubo, \& Boisard, 2000, in the long bones of ratites and Margerie et al., 2004, in the 
284 long bones of the king penguin). In other amniotes, the initial expansion of the cortex by 285 appositional growth is made of PFB including, if any, smaller cavities, and producing a slow volume expansion of the cortex (e.g., Castanet, 1978, in squamates). As a consequence, for the same quantity of osteoid produced, static osteogenesis and WB are associated to a higher rate of bone accretion (at the tissue level) than dynamic osteogenesis and PFB. At the cellular level, considering that in static osteogenesis stationary osteoblasts are oriented randomly, the WB matrix formed is highly porous (Stein \& Prondvai, 2014). In contrast, in dynamic osteogenesis, osteoblasts are all oriented in the same direction and produce PFB, a much more compact matrix (Stein \& Prondvai, 2014). Again, for the same quantity of osteoid produced, static osteogenesis will produce a higher rate of volume expansion than dynamic osteogenesis.

294 At the ultrastructural level, the absolute growth rates at which WB and PFB are formed depend on the osteoid secretion rate of, respectively, static osteogenesis osteoblasts and dynamic osteogenesis osteoblasts (Stein \& Prondvai, 2014). Considering that no ultrastructural differences have been observed between static and dynamic osteoblasts (Marotti, 2010), we expect to find similar osteoid secretion rates (Stein \& Prondvai, 2014).

299 The formation of a scaffold of WB incorporating large cavities at high rates and the perimedullary resorption of bone tissue by osteoclasts at high rates are both energy consuming

301 (Montes et al., 2007). Thus, these mechanisms are only possible in taxa characterized by high 302 resting metabolic rates (Fleischle et al., 2018; Legendre et al., 2016; Olivier et al., 2017).

303 According to Padian \& Horner (2002) "the types of tissue deposited in the bones of extinct 304 animals are the most direct evidence of basal metabolic rates, because they directly reflect 305 growth rates [...]. The sustained deposition of fast-growing bone tissues, as displayed by mammals, birds and other dinosaurs, must reflect sustained high basal metabolic rates." This

307 hypothesis was supported by the results obtained by Montes et al. (2007): the variation of 308 bone growth rates significantly explains the variation of resting metabolic rates in a sample of 
309 extant amniotes. In conclusion, precise quantifications of the proportion of WB is a key factor

310 for performing reliable paleobiological inferences of both bone growth rates and resting

311 metabolic rates.

312 Is WB content significantly different in the transverse and the longitudinal section planes?

313 Qualitatively, when a stripe or a patch of WB was identified in a transverse section, the

314 corresponding stripe or patch of WB was always found at the same location in the

315 corresponding longitudinal section (please find in supplementary file 2 pictures of all the

316 analyzed thin sections where WB areas, PFB areas and vascular canals were encircled).

317 Quantitatively, the proportion of WB is not significantly different in transverse and in

318 longitudinal sections (i.e., the Wilcoxon signed-rank non-parametric paired test did not reject

319 the null hypothesis suggesting that the proportion of WB is not significantly different in

320 transverse and in longitudinal sections).

321 Considering that traditional bone histology is a destructive method, and that performing

322 longitudinal sections (in addition to the transverse sections) involves the destruction of

323 supplementary volume of material, we recommend a three steps workflow to efficiently

324 establishing the proportion of WB in the diaphysis of an appendicular bone: (a) a careful

325 analysis of transverse sections to propose hypotheses of the presence of WB when we observe

326 the presence of canaliculi running radially from large irregular osteocyte lacunae, and general

327 isotropy at tissue scale, but local anisotropy at cellular scale; (b) performing and analyzing

328 longitudinal sections only in cases where an ambiguity remains; and (c) reanalyzing the

329 corresponding transverse sections.

330 Author contributions 
331 JC conceived and designed the study, MFB wrote a first draft of the manuscript and

332 performed quantifications and statistical tests. All three authors analyzed thin sections and

333 wrote the final version.

334 Acknowledgments

335 We thank Hayat Lamrous for having prepared the thin sections, Vivian de Buffrénil for

336 sharing his material on Caiman crocodilus and Damien Germain, curator of the vertebrate

337 hard tissues histological collection of the MNHN, for including the thin sections produced in

338 this study in that collection. We thank Edina Prondvai and two anonymous reviewers for their

339 constructive comments.

340 References

341 Botha-Brink, J., \& Smith, R. M. H. (2011). Osteohistology of the Triassis Archosauromorphs

342 Prolacerta, Porterosuchus, Eparkeria, and Erythrosuchus from the Karoo Basin of South

343 Africa. Journal of Vertebrate Paleontology, 31(6), 1238-1254.

344 https://doi.org/10.1080/039.031.0623

345 Bromage, T. G., Goldman, H. M., McFarlin, S. C., Warshaw, J., Boyde, A., \& Riggs, C. M.

346 (2003). Circularly Polarized Light Standards for Investigations of Collagen Fiber Orientation

347 in Bone. The Anatomical Record, 274(B), 157-168. https://doi.org/10.1002/ar.b.10031

348 Castanet, J. (1978). Les marques de croissance osseuse comme indicateurs de l'âge chez les

349 lézards. Acta Zoologica, 59, 35-48.

350 Castanet, J., Curry, K., Cubo, J., \& Boisard, J.-J. (2000). Periosteal bone growth rates in

351 extant ratites ( ostriche and emu ). Implications for assessing growth in dinosaurs. Comptes

352 Rendus de l'Académie Des Sciences - Series III - Sciences de La Vie, 323(6), 543-550.

353 https://doi.org/10.1016/S0764-4469(00)00181-5 
354 Cubo, J., Hui, M., Clarac, F., \& Quilhac, A. (2017). Static osteogenesis does not precede 355 dynamic osteogenesis in periosteal ossification of Pleurodeles (Caudata, Amphibia) and 356 Pogona (Squamata, Lepidosauria). Journal of Morphology, 278, 621-628.

357 https://doi.org/10.1002/jmor.20659

358 Cubo, J., \& Jalil, N.E. (2019). Bone histology of Azendohsaurus laaroussii: Implications for

359 the evolution of thermometabolism in Archosauromorpha. Paleobiology, 45(2), 317-330.

360 https://doi.org/10.1017/pab.2019.13

361 Cubo, J., Le Roy, N., Martinez-maza, C., \& Montes, L. (2012). Paleohistological estimation

362 of bone growth rate in extinct archosaurs. Paleobiology, 38(2), 335-349.

363 https://doi.org/10.5061/dryad.j2m25n82

364 Cubo, J., Woodward, H., Wolff, E., \& Horner, J. R. (2015). First Reported Cases of

365 Biomechanically Adaptive Bone Modeling in Non-Avian Dinosaurs. PLoS ONE, 10(7), 1-11.

366 https://doi.org/10.1371/journal.pone.0131131

367 De Margerie, E., Robin, J.-P., Verrier, D., Cubo, J., Groscolas, R., \& Castanet, J. (2004).

368 Assessing a relationship between bone microstructure and growth rate: a fluorescent labelling

369 study in the king penguin chick (Aptenodytes patagonicus ). The Journal of Experimental 370 Biology, 207, 869-879. https://doi.org/10.1242/jeb.00841

371 Ferretti, M., Palumbo, C., Contri, M., \& Marotti, G. (2002). Static and dynamic osteogenesis :

372 two different types of bone formation. Anatomy and Embryology, 206(1-2), 21-29.

373 https://doi.org/10.1007/s00429-002-0265-6

374 Fleischle, C. V., Wintrich, T., \& Sander, P. M. (2018). Quantitative histological models 375 suggest endothermy in plesiosaurs. PeerJ, 6, 25. https://doi.org/10.7717/peerj.4955 
376 Francillon-Vieillot, H., de Buffrénil, V., Castanet, J., Géraudie, J., Meunier, F., Sire, J. Y., ...

377 De Ricqlès, A. (1990). Microstructure and Mineralisation of Vertebrate Skeletal Tissues. In J.

378 G. Carter (Ed.), Skeletal Biomineralization: Patterns, Processes and Evolutionary Trends (pp. 379 471-530). New York: Van Nostrand Reinhold.

380 Houssaye, A. (2013). Bone histology of aquatic reptiles: What does it tell us about secondary

381 adaptation to an aquatic life? Biological Journal of the Linnean Society, 108(1), 3-21.

382 https://doi.org/10.1111/j.1095-8312.2012.02002.x

383 Houssaye, A., Lindgren, J., Pellegrini, R., Lee, A. H., Germain, D., \& Polcyn, M. J. (2013).

384 Microanatomical and Histological Features in the Long Bones of Mosasaurine Mosasaurs

385 (Reptilia, Squamata) - Implications for Aquatic Adaptation and Growth Rates. PLoS ONE,

$3868(10), 1-12$. https://doi.org/10.1371/journal.pone.0076741

387 Kerschnitzki, M., Wagermaier, W., Roschger, P., Seto, J., Shahar, R., Duda, G. N., ... Fratzl,

388 P. (2011). The organization of the osteocyte network mirrors the extracellular matrix 389 orientation in bone. Journal of Structural Biology, 173, 303-311.

390 https://doi.org/10.1016/j.jsb.2010.11.014

391 Laurin, M., \& de Buffrenil, V. (2016). Microstructural features of the femur in early

392 ophiacodontids: A reappraisal of ancestral habitat use and lifestyle of amniotes. Comptes

393 Rendus Palevol, 15, 115-127.

394 https://doi.org/10.1016/j.crpv.2015.01.001

395 Laurin, M., Canoville, A., \& Germain, D. (2011). Bone microanatomy and lifestyle : A

396 descriptive approach. Comptes Rendus Palevol, 10(5-6), 381-402.

397 https://doi.org/10.1016/j.crpv.2011.02.003 
398 Legendre, L. J., Guénard, G., Botha-Brink, J., \& Cubo, J. (2016). Palaeohistological Evidence 399 for Ancestral High Metabolic Rate in Archosaurs. Systematic Biology, 65(6), 989-996.

400 https://doi.org/10.1093/sysbio/syw033

401 Marotti, G. (2010). Static and dynamic osteogenesis. Italian Journal of Anatomy and $402 \quad$ Embryology, 115(1), 123-126.

403 Montes, L., le Roy, N., Perret, M., de Buffrenil, V., Castanet, J., \& Cubo, J. (2007).

404 Relationships between bone growth rate, body mass and resting metabolic rate in growing 405 amniotes: a phylogenetic approach. Biological Journal of the Linnean Society, 92, 63-76. 406 https://doi.org/10.1111/j.1095-8312.2007.00881.x

407 Olivier, C., Houssaye, A., Jalil, N.-E., \& Cubo, J. (2017). First palaeohistological inference of 408 resting metabolic rate in an extinct synapsid, Moghreberia nmachouensis (Therapsida:

409 Anomodontia). Biological Journal of the Linnean Society, 121, 409-419.

410 https://doi.org/10.1093/biolinnean/blw044

411 Padian, K., De Ricqlès, A. J., \& Horner, J. R. (2001). Dinosaurian growth rates and bird 412 origins. Nature, 412, 405-408. https://doi.org/10.1038/35086500

413 Padian, K., \& J. R. Horner. (2002). Typology versus transformation in the origin of birds.

414 Trends in Ecology and Evolution 17, 120-124.

415 https://doi.org/10.1016/S0169-5347(01)02409-0

416 Padian, K., Horner, J. R., \& De Ricqlès, A. J. (2004). Growth in small dinosaurs and 417 pterosaurs: the evolution of archosaurian growth strategies. Journal of Vertebrate

418 Paleontology, 24(3), 555-571. https://doi.org/10.1671/0272-

419 4634(2004)024[0555:GISDAP]2.0.CO;2 
420 Palumbo, C., Ferretti, M., \& Marotti, G. (2004). Osteocyte Dendrogenesis in Static and

421 Dynamic Bone Formation: An Ultrastructural Study. Anatomical Record - Part A Discoveries

422 in Molecular, Cellular, and Evolutionary Biology, 278(1), 474-480.

423 https://doi.org/10.1002/ar.a.20032

424 Prondvai, E., Stein, K. H. W., De Ricqlès, A., \& Cubo, J. (2014). Development-based revision 425 of bone tissue classification: The importance of semantics for science. Biological Journal of 426 the Linnean Society, 112(4), 799-816. https://doi.org/10.1111/bij.12323

427 Starck, J. M., \& Chinsamy, A. (2002). Bone microstructure and developmental plasticity in 428 birds and other dinosaurs. Journal of Morphology, 254, 232-246.

430 Stein, K., \& Prondvai, E. (2014). Rethinking the nature of fibrolamellar bone: an integrative 431 biological revision of sauropod plexiform bone formation. Biological Reviews, 89(1), 24-47. 432 https://doi.org/10.1111/brv.12041

$434 \quad$ Figure legends

435 Figure 1. Transverse thin sections of the femur of Capreolus capreolus observed in cross 436 polarized light with lambda wave plate. White arrow: woven bone showing microlamellar 437 arrangement in former osteoblast secretory territories (fibers are anisotropic and appear blue 438 where they are perpendicular to the axis of light propagation); Black arrow: vascular cavity. 439 White arrowhead: lamellar bone lining vascular cavities in primary oteons; Black arrowhead: 440 parallel-fibered bone with fibers oriented parallel to the axis of light propagation in primary 441 osteons. Periosteum is on the top. Scale bars equal $100 \mu \mathrm{m}$. 
444 Figure 2. Transverse (A, B, E, F) and longitudinal (C, D, G, H) thin sections of the femora of 445 Capreolus capreolus (A-D) and Gallus gallus (E-H) in linearly polarized light (A, C, E, G)

446 and cross polarized light with lambda wave plate (B, D, F, H). White arrows: woven bone;

447 black arrow: radial anastomosis between circumferential canals; white arrowheads: lamellar 448 bone; black arrowheads: parallel-fibered bone. Periosteum is on the left for A to F and top left 449 corner for $\mathrm{G}$ and $\mathrm{H}$. Scale bars equal $100 \mu \mathrm{m}$.

Figure 3. Transverse (A, B, E, F) and longitudinal (C, D, G, H) thin sections of the femora of

452 Crocodylus niloticus (A-D) and Zootoca vivipara (E-H) in linearly polarized light (A, C, E,

$453 \mathrm{G})$ and cross polarized light with lambda wave plate (B, D, F, H). White arrow: primary 454 osteon; black arrows: simple vascular canals; white arrowheads: endosteal bone; black 455 arrowheads: woven bone. Periosteum is on the right. Scale bars equal $100 \mu \mathrm{m}$.

Figure 4. Transverse (A, B, E, F) and longitudinal (C, D, G, H) thin femoral sections of Lystrosaurus sp. (A-D) and Oudenodon bainii (E-H) in linearly polarized light (A, C, E, G) and cross polarized light with lambda wave plate $(\mathrm{B}, \mathrm{D}, \mathrm{F}, \mathrm{H})$. White arrow: primary osteon;

460 black arrows: simple vascular canals; white arrowheads: endosteal bone; black arrowheads:

461 woven bone. Periosteum is on the top right corner in A, B, E, F, and on the top in C, D, G, H.

462 Scale bars equal $100 \mu \mathrm{m}$. 